\title{
Prevention and Control Strategy of Reader Factors in Safety Management of Electronic Reading Room
}

\author{
Yanping Dong* \\ Zhongyuan University of Technology, Zhengzhou, Henan Province, China
}

*Corresponding author: Yanping Dong, 962103229@qq.com

\begin{abstract}
Many libraries have built and opened the electronic reading room, electronic reading room security management has been paid more and more attention. In the specific safety management, the prevention and control of reader factors is very important. By comparing and analyzing the prevention and control of reader factors in the safety management of some electronic reading rooms, it can be found that the corresponding prevention and control situation is not ideal, and even there are some obvious problems, which also leads to great hidden dangers in the safety management level. This paper will specifically analyze the prevention and control of reader factors in the safety management of electronic reading room, and put forward more effective prevention and control strategies.
\end{abstract}

Keywords: Electronic reading room; Safety management; Readers

Publication date: September 2021; Online publication: September 30, 2021

\section{Introduction}

The number of domestic electronic reading rooms is extremely large. In the safety management of electronic reading rooms, the importance of reader factor prevention and control is increasing. It can be found that the prevention and control of reader factors in the corresponding safety management is not ideal, and there are some obvious problems in the specific prevention and control process. It can be predicted that in the future, the number of electronic reading rooms will be further increased, and the pressure at the level of safety management will be further increased. It is also necessary to explore effective strategies for the prevention and control of reader factors in safety management.

\section{Introduction on Precaution and Control of Reader Factors in Safety Management of Electronic Reading Room}

The importance of preventing and controlling reader factors in the safety management of electronic reading rooms is self-evident, which is also the direct reason why many electronic reading rooms have made corresponding attempts in operation and safety management ${ }^{[1]}$. By analyzing the common security incidents in electronic reading room, it can be found that readers are often the direct causes of specific security incidents. Such as bringing some contraband, improper operation and so on are easy to lead to specific security incidents, which is bound to have a great impact on the inherent security management of the electronic reading room. Better standing in safety management is to better control the possibility of safety events caused by reader factors after the prevention and control of reader factors. At present, the prevention and control of reader factors in the safety management of electronic reading room is not ideal, and there are some obvious common problems in specific practice. As for the operation and management subjects of electronic reading rooms, they also need to think more deeply about the prevention and control of reader factors in safety management. 


\section{Problems Existing in Precaution and Control of Reader Factors in Safety Management of Electronic Reading Room}

\subsection{Entrance safety inspection is not in place}

In the security management of electronic reading room, the security check at the entrance is not in place, which is also a representative problem in the prevention and control of reader factors. Some readers are easy to carry lighters and other contraband into the electronic reading room, and some canned cosmetics are also easy to carry into the electronic reading room. After these inflammables and explosives are brought into the electronic reading room, they will inevitably increase the risk of safety events. In contrast, most electronic security checks at the entrance of most electronic reading rooms are not in place and are not standard. What's more, because the lighter and other contraband items are not temporarily withheld at the entrance, many readers are easy to secretly smoke in the bathroom of the electronic reading room, and the probability of fire and other accidents is also greatly increased, which increases the corresponding pressure of safety management ineffectively. From this perspective, the inadequate entrance safety inspection and the weak seizure of contraband have also become deficiencies in the prevention and control of reader factors in safety management, and even directly lead to the long-term existence of corresponding potential safety hazards.

\subsection{The condition of reader operation instruction is poor}

In many electronic reading rooms, readers' terminal operation guidance is poor. From the perspective of reader factor prevention and control in safety management, the lack of effective guidance for reader operation has also become a significant problem ${ }^{[2]}$. Many readers are unfamiliar with the electronic reading rooms, and it is difficult for them to operate independently without the help of the specific self-service query terminal and electronic reading systems. In this case, the wrong operation and improper operation not only easily lead to the electronic reading room hardware damage, but also easily lead to the system crash. In the vast majority of electronic reading rooms, the actual situation is not combined with the reader operation guidance, some readers who obviously lack experience in terminal use, system use experience cannot get effective guidance and help. In this case, improper operation of the reader has become a potential safety hazard in safety management. Not only that, some readers will choose the online query solution when they can't operate well, and entering the phishing website by mistake will threaten the security of book resources and data in the E-reading room.

\subsection{The publicity effect of safety management is not ideal}

In the safety management of electronic reading room, the publicity related to safety management is not in place, and it is an indisputable fact that the publicity effect of safety management is relatively poor. In the subconscious of many readers, they will not regard the reader factor as a hidden danger in the safety management of the electronic reading room, and they also lack a clear understanding of the prevention and control of the reader factor in the safety management of the electronic reading room. In this case, the electronic reading room has become the only safety management subject. In the prevention and control of reader factors, the real participation of readers is very low. Different readers have obvious individual differences, their safety awareness is not the same, and there are great differences in their understanding of safety management inside electronic reading rooms. Once the electronic reading rooms' propaganda ignores the specific safety management, or safety management effect is not ideal, it is difficult for readers to have a good grasp of the correct and wrong terminal and equipment usage specifications, and it is also difficult to clarify the safety accidents, which is not conducive to the formation of reader factor prevention and control environment in safety management, and even will increase the actual difficulty of reader factor prevention and control in safety management. 


\subsection{The effectiveness of technical preventive measures is low}

In the security management of the electronic reading rooms, some readers can easily browse some irregular websites driven by the psychology of curiosity, lust and so on. Some readers use the computer in the electronic reading room to download some resources and install some software, which can also easily lead to the invasion of Trojans and viruses ${ }^{[3]}$. Some Trojans and viruses will not only invade the computer terminal, but also likely invade the electronic reading system or online resource library. From the point of view of safety management, the technical preventive means in the prevention and control of reader factors are relatively few, and the actual effectiveness of existing technical preventive means is obviously insufficient. The electronic reading rooms of some university libraries tend to guard against external Trojans and viruses with the help of LAN. However, with the large area of mobile Wifi and Wifi signal portable devices, readers can still easily use the computers in the electronic reading room to connect to the external network. Due to the lack of firewalls with good prevention effect, the technical prevention means are single and low in effectiveness, the improper operations of readers are easily directly transformed into specific safety accidents, and the prevention and control effect of readers' factors in safety management is naturally poor.

\section{Specific Prevention and Control Strategy of Reader Factors in Safety Management of Electronic Reading Room}

\subsection{Strengthen entrance security checks}

In the safety management of the electronic reading room, it is necessary to strengthen the security inspection of the entrance, especially in the perspective of the prevention and control of readers' factors. The security inspection of the entrance can better avoid all kinds of contraband appearing in the electronic reading room. Specifically, security inspection equipment shall be added at the entrance of the electronic reading room, and the readers entering the electronic reading rooms shall be subject to security inspection with the help of security inspection equipment. In the entrance safety inspection, the following items need to be the key inspection objects (as shown in Table 1.).

Table 1. Main Objects (Items) of security inspection at the entrance of electronic Reading Rooms

\begin{tabular}{|l|lr|l|l|l|}
\hline Item category & \multicolumn{2}{|l|}{ Control items } & Flammable items & Explosive items & Pollutable items \\
\hline $\begin{array}{l}\text { Representative } \\
\text { items }\end{array}$ & $\begin{array}{l}\text { Cutting tools, } \\
\text { sharp } \\
\text { objects, etc }\end{array}$ & $\begin{array}{l}\text { Lighters, tobacco, } \\
\text { etc }\end{array}$ & $\begin{array}{l}\text { Inflator pump, } \\
\text { power bank, } \\
\text { canned sprays, etc. }\end{array}$ & $\begin{array}{l}\text { Ink and other } \\
\text { colored liquids }\end{array}$ \\
\hline
\end{tabular}

With the addition of security inspection equipment, inflammable and explosive items such as lighters and large-capacity charging kits carried by readers can be checked, so that security incidents such as fire caused by contraband can be better avoided. Not only that, the entry of the electronic reading rooms, and the room also need to add enough fire smoke sensor, electronic camera, to assist the corresponding safety management. The addition and use of these safety management devices can also help the electronic reading room to better prevent and control the reader factors, and contribute to the comprehensive safety management, as well as the improvement of safety management efficiency.

\subsection{Strengthen readers' operation guidance and demonstration}

Within the safety management framework of the electronic reading room, it is necessary to strengthen the operation guidance and demonstration of readers in the prevention and control of readers' factors, so as to avoid the occurrence of safety management events caused by readers' wrong and improper operations ${ }^{[4]}$. 
Specifically, the corresponding operation process poster can be posted at the entrance of the electronic reading rooms and near the self-service inquiry terminal to clarify the key operational points and explain them in detail, so as to help readers better master the self-service terminal equipment and the use skills of the electronic reading system. The electronic reading room can also produce the operation instruction demonstration video or Flash animation, and set the jump QR code link, so that readers can be better familiar with the general operation process by scanning the code. Some large electronic reading rooms can also add readers operation guidance posts, so that the relevant personnel can provide readers with some specific self-help equipment use, as well as computer use help. With the continuous improvement of readers' operation ability and standardized operation consciousness, the prevention and control conditions of readers' factors in the safety management of electronic reading room will be better and better, and the corresponding safety management pressure can be better relieved.

\subsection{Do a good job in safety management publicity}

In order to do a good job in the prevention and control of readers' factors in the safety management of electronic reading rooms, it is also very important to do a good job in the publicity of safety management. Generally speaking, the publicity of safety management of the readers, the awareness of safety management of the readers, and the self-restraint from the perspective of safety management in the electronic reading room can also create a better safety management environment. For example, on the computer desktop in the electronic reading rooms, it is also desirable to take the main contents of safety management and safety rules as the desktop background and post some specific safety management requirements and relevant posters and notices on the surrounding walls. In addition, the electronic reading room can also broadcast some specific security management broadcasts on time on the hour to deepen readers' understanding and cognition of the security management requirements in the electronic reading room. In the electronic reading room of some university libraries, all departments should also undertake the publicity of the library and the safety management knowledge in the electronic reading room, so that the main reader group of teachers and students can have a higher awareness of safety management. Once the safety management carried out by the reader can be connected with the safety management carried out by the electronic reading room, the prevention and control of the reader factors will become simpler.

\subsection{Technical prevention relying on firewall upgrade}

Relying on the firewall upgrade to do a good job of the corresponding technical prevention is very important, especially in some large electronic reading rooms, only relying on the traditional reader factors prevention and control strategy is difficult to provide enough security for the electronic reading room management. Therefore, it is also desirable to combine the traditional reader factor prevention and control strategy with the selection of technical strategy, and carry out safety management from different angles. For example, an electronic reading room embedded a firewall in the internal LAN, building an internal safety management system based on firewall. With the help of the better construction of the corresponding system and the continuous upgrading of the firewall technology, the technical means have also become a specific way to prevent and control the reader factors in the security management of the electronic reading room. Therefore, the domestic electronic reading rooms need to combine their own reality, give more effective application of firewall system, namely virus interception and killing technology, in safety management.

\section{Conclusion}

The prevention and control of reader factors in the safety management of library electronic reading rooms need to be considered in many aspects. The main body of safety management should not only make corresponding planning, but also carry out the prevention and control practice of reader factors from 
multiple angles. Moreover, in the specific safety management, we should also do a good job in phased examination, review and analysis, focus on the problems existing in the prevention and control of readers' factors, and take the process of solving a series of problems as the process of continuously improving the level of safety management. More importantly, with the continuous solution of the corresponding problems, the safety management subject can also accumulate more reader factor prevention and control experience, which can also better guide the follow-up safety management practice activities.

\section{Disclosure statement}

The author declares no conflict of interest.

\section{References}

[1] Shan XL., 2019, On Reader Service in Electronic Reading Room of Library. The Guide of Science and Education - Electronic Edition (midmonth), (08): 264.

[2] Liu M., 2020, Analysis on Security Management Strategy of Library Digital Information. Information Weekly, (03): 1-1.

[3] Lu XY., 2019, Personnel Management of Electronic Reading Room after Free Opening -- Taking the Electronic Reading Room of a Normal University Library in North Anhui as an Example. Journal of West Anhui University, (04): 45-46.

[4] Fan Y., 2020, Discussion on the Construction and Management of Electronic Reading Room in Library. Digital Communication World, (04): 231-232. 